\title{
Blood manganese concentrations in Jamaican children with and without autism spectrum disorders
}

Mohammad H Rahbar ${ }^{1,2,3^{*}}$, Maureen Samms-Vaughan ${ }^{4}$, Aisha S Dickerson ${ }^{3}$, Katherine A Loveland ${ }^{5}$, Manouchehr Ardjomand-Hessabi ${ }^{3}$, Jan Bressler ${ }^{6}$, Sydonnie Shakespeare-Pellington ${ }^{4}$, Megan L Grove ${ }^{6}$, Deborah A Pearson ${ }^{5}$ and Eric Boerwinkle ${ }^{1,6}$

\begin{abstract}
Background: Manganese is an essential element for human health and development. Previous studies have shown neurotoxic effects in children exposed to higher levels of manganese. Autism Spectrum Disorder (ASD) is a neurodevelopmental disorder that impairs social interaction and communication. Several studies have hypothesized that ASD is caused through environmental exposures during crucial stages in brain development. We investigated the possible association between blood manganese concentrations (BMC) and ASD. We also identified factors associated with BMC in typically developing (TD) Jamaican children.
\end{abstract}

Methods: We used data from 109 ASD cases with their 1:1 age- and sex-matched TD controls to compare mean BMC in Jamaican children (2-8 years of age) with and without ASD. We administered a pre-tested questionnaire to assess demographic and socioeconomic information, medical history, and potential exposure to manganese. Finally, we collected $2 \mathrm{~mL}$ of whole blood from each child for analysis of manganese levels. Using General Linear Models (GLM), we assessed the association between BMC and ASD status. Furthermore, we used two independent sample t-tests to identify factors associated with BMC in TD children.

Results: In univariable GLM analysis, we found no significant association between BMC and ASD, $(10.9 \mu \mathrm{g} / \mathrm{L}$ for cases vs. $10.5 \mu \mathrm{g} / \mathrm{L}$ for controls; $P=0.29$ ). In a multivariable GLM adjusting for paternal age, parental education, place of child's birth (Kingston parish), consumption of root vegetables, cabbage, saltwater fish, and cakes/buns, there was still no significant association between BMC and ASD status, $(11.5 \mu \mathrm{g} / \mathrm{L}$ for cases vs. $11.9 \mu \mathrm{g} / \mathrm{L}$ for controls; $P=0.48)$. Our findings also indicated TD children who ate fresh water fish had a higher $B M C$ than children who did not $(11.0 \mu \mathrm{g} / \mathrm{L}$ vs. $9.9 \mu \mathrm{g} / \mathrm{L} ; P=0.03)$ as younger TD children (i.e., $2 \leq$ age $\leq 4),(12.0 \mu \mathrm{g} / \mathrm{L}$ vs. $10.2 \mu \mathrm{g} / \mathrm{L}$; $P=0.01)$.

Conclusions: While these results cannot be used to assess early exposure at potentially more susceptible time period, our findings suggest that there is no significant association between manganese exposures and ASD case status in Jamaica. Our findings also indicate that BMC in Jamaican children resemble those of children in the developed world and are much lower than those in the developing countries.

Keywords: Manganese, Autism Spectrum Disorder, Neurodevelopment, Seafood, Vegetables, Jamaica

\footnotetext{
* Correspondence: Mohammad.H.Rahbar@uth.tmc.edu

${ }^{1}$ Division of Epidemiology, Human Genetics, and Environmental Sciences (EHGES), University of Texas School of Public Health at Houston, Houston, Texas, USA

${ }^{2}$ Division of Clinical and Translational Sciences, Department of Internal Medicine, University of Texas Medical School at Houston, Houston, Texas 77030, USA

Full list of author information is available at the end of the article
} 


\section{Background}

Autism Spectrum Disorder (ASD) is a neurodevelopmental disorder that impairs social interaction and communication [1-3]. Currently, the etiology of ASD is not well understood. A number of studies have indicated that ASD has a heritable factor $[4,5]$. Others have suggested that there are combinations of factors that influence the etiology of ASD [6-8], including the interaction of genes with environmental factors [9]. Furthermore, studies have also hypothesized that ASD are caused through environmental exposures during crucial stages in brain development [10].

Manganese $(\mathrm{Mn})$ is a naturally occurring trace element essential for human health and development $[11,12]$. On the other hand, excess exposure to manganese could cause neurotoxicity, which will be described in detail below [12-26]. Inorganic compounds, such as manganese phosphate, manganese sulfate, and manganese oxides, can be formed during combustion processes in coal-burning industrial facilities and automobile motors [11]. Exposure to these compounds through ambient air is of concern because there is greater neurotoxicity from inhaled manganese than from orally ingested manganese [27]. This is due to biological absorption though the lungs or olfactory epithelium, allowing manganese to bypass the liver and go directly to the brain [28]. Previous studies have reported that levels of manganese found in Jamaican soil are approximately twice the average levels reported for soils in other countries based on a world-wide comparison performed by the International Atomic Energy Agency [29]. Free $\mathrm{Mn}^{2+}$ ions are readily absorbed by plants and can be easily exchanged with $\mathrm{Ca}^{2+}$, making fruits, vegetables, and grains primary nutritional sources of manganese $[12,30,31]$. In Jamaica, the concentration of manganese in legumes has been reported, with the highest concentration in cowpeas [31]. On the other hand, manganese and other heavy metals can accumulate in tissues of fish and bottomfeeding mollusks, posing a risk to human health [32-34], with a higher risk in those residing in coastal communities where local fish consumption is greater [32-34].

Excess exposure or deficiency of manganese can cause harmful effects in children [24]. Intake of adequate amounts of manganese is usually maintained through a balanced diet; insufficient amounts can lead to poor developmental outcomes, including slowed growth [12,35,36]. This occurrence in children is very rare, however, the effects of deficient manganese exposure in humans are not well documented $[37,38]$.

Children have a higher rate of absorption and/or retention of manganese compared to adults [12]. Manganese primarily targets the nervous system and has been shown to have adverse effects on neuromuscular [12] and cognitive function [13] in adults exposed to excessive amounts. Other studies have also shown adverse neurological effects in children exposed to higher levels of manganese including increased behavioral problems [14-16], reduced verbal and full-scale intelligence quotient (IQ) scores [17-21], diminished attention [22], and lower academic achievement $[23,24]$. In a study on children (12 months of age) from Mexico City, Claus Henn et al. [25] reported an inverted U-shaped association between blood manganese concentrations (BMC) and concurrent mental development scores [25] which supports a recent report that both low and high manganese levels may have adverse effects on neurodevelopment in early life [24].

Several studies have examined the relationship between ASD and manganese exposure as measured by air distribution [39], tooth enamel [40], hair [40-45], urine [44], and red blood cells [46], but their findings are conflicting. For instance, a case-control study of 84 children (ages 9-14 years) recruited from two multi-site national research studies in the US reported that mean manganese concentrations in postnatal regions of tooth enamel in children with ASD was lower in comparison to levels in primary teeth of typically developing (TD) children matched on gender, race, parents' education, and parents' marital status (1.87 ppm vs. $2.91 \mathrm{ppm}, P=0.08$ ) [40]. In contrast, another case-control study of 44 children with ASD and 61 age-balanced controls showed no difference in the distributions of manganese in hair between ASD cases and TD controls $(P=0.84)$ [43].

As an island nation with a unique soil composition [29], Jamaica offers the opportunity to study effects of exposures to various environmental contaminants. In this study, we investigated the possible association between $\mathrm{BMC}$ and ASD status. As a second objective, we also identified factors associated with BMC in TD Jamaican children.

\section{Materials and methods \\ General description}

The Jamaican Autism study is an age- and sex-matched case-control study that began enrollment in December 2009 , with an aim to investigate possible associations between ASD and postnatal environmental exposure to five heavy metals of interest: lead, mercury, arsenic, cadmium, and manganese. Details regarding recruitment and screening of children have been reported previously [47-50]. In summary, children listed in the University of West Indies' (UWI) Jamaica Autism Database who were identified as being at risk for having an ASD based on assessment from trained clinicians using the Diagnostic and Statistical Manual of Mental Disorders-Text Revision (DSM-IV-TR) criteria [51] and the Childhood Autism Rating Scale (CARS) [52] were invited for reassessment of ASD. Parents who provided consent were administered the Autism Diagnostic Interview-Revised (ADI-R) [53] and their children underwent assessment using the Autism Diagnostic Observation Schedule (ADOS) [54] to confirm the previously suggested diagnosis using established algorithms and 
cut-off points for scoring the ADOS [55] and ADI-R [56]. Inclusion criteria for the study included birth in Jamaica and age between 2 and 8 years at enrollment. Age- and sex- matched TD controls from schools and well-child clinics were then identified for each confirmed ASD case. We also administered the Lifetime Form of the Social Communication Questionnaire (SCQ) [53] to parents or guardians of TD controls to screen for symptoms of ASD and included those with an SCQ score of 0-6, 6 being one standard deviation above the mean SCQ score of TD children [57].

Before enrollment, all parents and guardians provided written informed consent in compliance with the Institutional Review Boards of the University of Texas Health Science Center at Houston and UWI. We then administered pre-tested demographic and food frequency questionnaires to parents or guardians of all children participating in the study to gather information on socioeconomic (SES) characteristics and potential exposure to manganese through nutritional intake. Food frequency questionnaires asked how often the child ate certain foods each week, with a particular focus on types of fruits, vegetables, grains, and proteins $[47,49,50]$. We collected $2 \mathrm{~mL}$ of venous whole blood from each child at the end of each interview. These blood samples were frozen and stored at $-20^{\circ} \mathrm{C}$, then shipped to the Michigan Department of Community Health $(\mathrm{MDCH})$ Trace Elements Laboratory for analysis of exposure to metals of interest. The data presented here are from the analysis of 218 children (109 ASD cases and 109 age- and sex-matched TD controls) that were evaluated between December 2009 and March 2012.

\section{Assessment of manganese exposure}

Jamaican soils contain a unique distribution of a variety of trace elements, including manganese that can accumulate in crops and seafood [29,31]. Because the Jamaican population consumes large amounts of locally grown fruits and vegetables along with large amounts of seafood [31], the residents may have continuous exposure to manganese, resulting in bioaccumulation [58]. For this study, venous whole blood samples were diluted and analyzed using a PerkinElmer Elan DRCII inductively-coupled plasma mass spectrometer (PerkinElmer, Waltham, MA). Assays for blood manganese were performed at the MDCH Trace Metals Laboratory, a facility certified by the Centers for Disease Control and Prevention (CDC) for trace metal analyses. All BMC in our samples are above the limit of detection of $1 \mu \mathrm{g} / \mathrm{L}$.

\section{Statistical analysis}

We used descriptive analyses to compare demographic characteristics and SES of enrolled ASD cases and TD controls. Since the distribution of BMC was approximately normal, we did not transform the manganese data. Therefore, the means reported are arithmetic means. To account for the age- and sex-matched study design when comparing BMC of ASD cases and TD controls, we used General Linear Models (GLM), which are equivalent to standard linear regression models with normality assumption of the residuals but allow assessment of random effects. As described in our earlier reports, we further controlled for the effect of matching by using 108 dummy variables and one referent pair to represent the $109^{\text {th }}$ matched pair $[47,49]$. To avoid multicollinearity due to high correlation between maternal and paternal education levels, we combined these variables into one binary variable indicating if at least one parent had education beyond high school or both parents had education up to high school. To test associations between ASD case status and exposure variables we used Conditional Logistic Regression (CLR). We also used GLMs to evaluate the association between blood manganese concentrations and potential exposures to manganese, including frequency of consumption of various food items by children. Furthermore, we used t-tests to assess the same associations for ASD and TD control groups separately.

Lastly, we fit a multivariable GLM to investigate the relationship between ASD and BMC in children while adjusting for potential confounders. To identify possible confounders that were included in our final multivariable model, we determined variables to be potentially associated with ASD case status if $P<0.25$ in the CLR model and potentially associated with BMC if $P<0.25$ in the GLM. The covariates were considered to be potential confounders if they changed the regression coefficient by $>10 \%$, and were then included in the final multivariable analysis [59]. We examined the role of potential confounders associated with various sources of manganese exposure including consumption of root vegetables, leafy vegetables, legumes, fruits, seafood, and grain products as well as drinking and cooking water source, parental ages, and parental education levels. Additionally, because a disproportionate number of our controls were drawn from the Kingston area and parental education level is a known factor associated with ASD, place of child's birth (Kingston parish vs. other parishes) and parental education level were considered as a priori potential confounders in our multivariable model. Finally, we categorized the BMC into four quartiles and assessed the possible association between the categorized BMC variable and ASD status by univariable and multivariable CLR models and using the lowest $25 \%$ of BMC as the referent category. The purpose of these alternative analyses is to provide estimates for unadjusted and adjusted matched odds ratios that will allow comparisons of our findings with those of other case-control studies. All statistical analyses were conducted at the 0.05 level of significance using SAS 9.3 ${ }^{\circ}$ statistical software [60]. 


\section{Results}

The mean age of children in our sample was approximately 67 months. Of the 218 children recruited, 184 (84.4\%) were male. ASD cases and TD controls were $92.7 \%$ and $99.1 \%$ Afro-Caribbean, respectively. Maternal and paternal education levels beyond high school for both parents were significantly lower in TD controls compared to ASD cases $(23.6 \%$ vs. $48.6 \%$ for mothers and $12.4 \%$ vs. $45.3 \%$ for fathers; $P<0.01$ ). The percentage of TD controls born in Kingston parish was significantly greater than in other parishes $(69.7 \%$ vs. $20.2 \% ; P<0.01)$. Additionally, compared to the ASD group, a greater percentage of families of the TD control group had three or more children in the household (46.8\% of controls and $21.1 \%$ of cases; $P<0.01$ ). The socioeconomic status of the ASD group, measured by reported possessions, was also higher than that of TD controls. Other demographic characteristics are displayed in Table 1.

Univariable analysis of the relationship between BMC and ASD case status showed no statistically significant difference between mean BMC in ASD cases compared to TD controls $(10.9 \mu \mathrm{g} / \mathrm{L}$ for ASD cases vs. $10.5 \mu \mathrm{g} / \mathrm{L}$ for TD controls, $P=0.29$ ). We used CLR to investigate potential associations between various sources of exposure and ASD status. Both maternal and paternal age were higher for ASD cases than TD controls [Matched Odds Ratio $(\mathrm{MOR})=3.13,95 \% \mathrm{CI}(1.41,6.93)$ for maternal age and $\mathrm{MOR}=2.54,95 \% \mathrm{CI}(1.34,4.82)$ for paternal age]. Parental education levels were also significantly higher for ASD cases compared to TD controls $[\mathrm{MOR}=3.36,95 \%$ CI $(1.85,6.10)]$. We also identified dietary intake differences between ASD cases and TD controls. For example, parents indicated that TD controls had a significantly higher consumption of fruits, vegetables, grains, and seafood than ASD cases, except for string beans, rice, shellfish, and shrimp as well as whole wheat bread, root vegetables ("yam, sweet potato, or dasheen"), and fresh water fish that were marginally significant. Associations between various exposure variables and ASD status are presented in Table 2.

Table 1 Demographic and socioeconomic characteristics of children and their parents by ASD status

\begin{tabular}{|c|c|c|c|c|}
\hline \multirow[t]{2}{*}{ Variables } & \multirow[t]{2}{*}{ Categories } & \multirow{2}{*}{$\begin{array}{l}\text { ASD Case }(n=109) \\
N(\%)\end{array}$} & \multirow{2}{*}{$\begin{array}{l}\text { TD Control }(n=109) \\
N(\%)\end{array}$} & \multirow[t]{2}{*}{$P$-value } \\
\hline & & & & \\
\hline Sex of child & Male & $92(84.4)$ & $92(84.4)$ & 1.00 \\
\hline \multirow[t]{3}{*}{ Age of child (months) } & Age $<48$ & $21(19.3)$ & $18(16.5)$ & 0.29 \\
\hline & $48 \leq$ age $<72$ & $49(45.0)$ & $50(45.9)$ & \\
\hline & Age $\geq 72$ & $39(35.7)$ & $41(37.6)$ & \\
\hline \multirow[t]{2}{*}{ Place of child's birth } & Kingston parish & $22(20.2)$ & $76(69.7)$ & $<0.01$ \\
\hline & Other parishes & $87(79.8)$ & $33(30.3)$ & \\
\hline \multirow[t]{2}{*}{ Maternal education ${ }^{a}$ (at child's birth) } & Up to high school ${ }^{*}$ & $56(51.4)$ & $81(76.4)$ & $<0.01$ \\
\hline & Beyond high school $^{* *}$ & $53(48.6)$ & $25(23.6)$ & \\
\hline \multirow[t]{2}{*}{ Paternal education ${ }^{b}$ (at child's birth) } & Up to high school* & $58(54.7)$ & $92(87.6)$ & $<0.01$ \\
\hline & Beyond high school ${ }^{*}$ & $48(45.3)$ & $13(12.4)$ & \\
\hline \multirow[t]{2}{*}{ Number of children in the household (Age $\leq 18$ years) } & $1-2$ & $86(78.9)$ & $58(53.2)$ & $<0.01$ \\
\hline & $\geq 3$ & $23(21.1)$ & $51(46.8)$ & \\
\hline \multirow[t]{2}{*}{ Number of adults in the household $\left(\right.$ Age $>18$ years) ${ }^{c}$} & $1-2$ & $72(66.1)$ & $65(60.7)$ & 0.47 \\
\hline & $\geq 3$ & $37(33.9)$ & $42(39.3)$ & \\
\hline \multirow[t]{8}{*}{ Assets owned } & TV & $107(98.2)$ & $102(93.6)$ & 0.10 \\
\hline & Refrigerator & $106(97.2)$ & $93(85.3)$ & $<0.01$ \\
\hline & Freezer & $14(12.8)$ & $21(19.3)$ & 0.20 \\
\hline & Living room set & $91(83.5)$ & $51(46.8)$ & $<0.01$ \\
\hline & Washing machine & $79(72.5)$ & $57(52.3)$ & $<0.01$ \\
\hline & Cars or other vehicle & $72(66.1)$ & $39(35.8)$ & $<0.01$ \\
\hline & Telephone/Cell phone & $109(99.1)$ & $108(99.1)$ & 1.00 \\
\hline & Cable/Satellite connection & $68(62.4)$ & $40(36.7)$ & $<0.01$ \\
\hline
\end{tabular}

"Up to high school education includes: attended primary, junior-secondary, and secondary/high/technical schools.

**Beyond high school education includes: attended vocational, tertiary college, or university.

${ }^{a}$ Maternal education was missing for 3 controls.

${ }^{b}$ Paternal education was missing for 3 cases and 4 controls.

${ }^{c}$ Number of adults in the household was missing for 2 control families. 
Table 2 Association between potential confounders and ASD case status using Conditional Logistic Regression (CLR) (218 children, 109 matched-pairs)

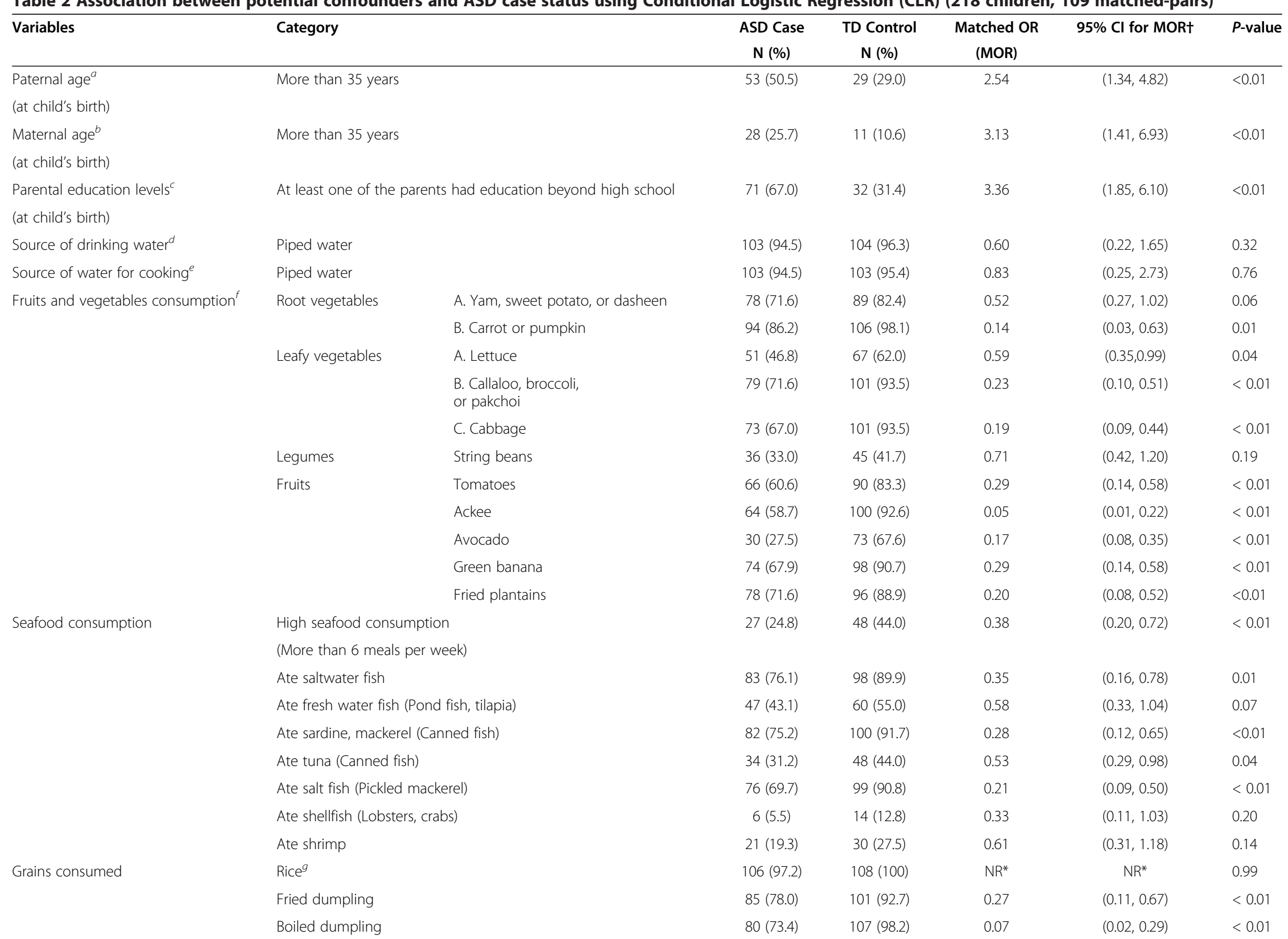


Table 2 Association between potential confounders and ASD case status using Conditional Logistic Regression (CLR) (218 children, 109 matched-pairs) (Continued)

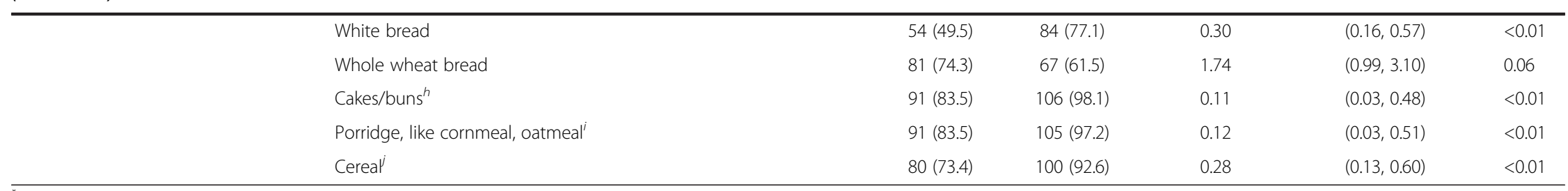

${ }^{7} \mathrm{NR}=$ Not reported because all children in the TD control group reported eating rice.

${ }^{+}$If a $95 \% \mathrm{Cl}$ for the MOR does not include one, then we conclude a significant association at $5 \%$ level.

${ }^{a}$ Paternal age was missing for 4 cases and 9 controls.

${ }^{b}$ Maternal age was missing for 5 controls.

cParental education levels were missing for 3 cases and 7 controls.

${ }^{d}$ Source of drinking water was missing for 1 control.

${ }^{e}$ Source of water for cooking was missing for 1 control.

${ }^{f}$ Fruits and vegetables consumption was missing for 1 control.

${ }^{9}$ Rice consumption was missing for 1 control.

${ }^{h}$ Cakes/buns consumption was missing for 1 control.

'Porridge consumption was missing for 1 contro

${ }^{j}$ Cereal consumption was missing for 1 control. 
In the process of examining potential confounders, we assessed the association of various exposure variables and BMC by GLMs. For example, we observed a significant $(P=0.02)$ association between paternal age and BMC. The results of t-tests revealed that mean BMC of TD children were 2 to 4 years of age was significantly higher than that of children 5 to 8 years of age $(12.0 \mu \mathrm{g} / \mathrm{L}$ vs. $10.2 \mu \mathrm{g} / \mathrm{L} ; P=0.01)$. Additionally, TD children who ate fresh water fish (pond fish, tilapia) had significantly higher BMCs than TD children who did not eat such fish $(11.0 \mu \mathrm{g} / \mathrm{L}$ vs. $9.9 \mu \mathrm{g} / \mathrm{L} ; P=0.03)$. However, the results of t-tests assessing similar associations for the ASD cases did not reveal any significant associations, except for ASD cases with higher parental education levels that had a marginally lower mean BMC $(10.5 \mu \mathrm{g} / \mathrm{L}$ vs. $11.6 \mu \mathrm{g} / \mathrm{L} ; P=0.06)$, compared with ASD cases whose parents both had education up to high school. Associations of exposure variables and BMC are shown in Table 3.

In our final multivariable GLM analysis, we compared mean BMC of ASD cases and TD controls after adjusting for paternal age, parental education, place of child's birth (Kingston parish vs. other parishes), consumption of root vegetables ("yam, sweet potato, or dasheen"), "cabbage", salt water fish, and cakes/buns. Our final multivariable models revealed that after controlling for the aforementioned potential confounders, there was no significant difference in mean BMC between ASD cases and TD controls $(11.5 \mu \mathrm{g} / \mathrm{L}$ for ASD cases and $11.9 \mu \mathrm{g} / \mathrm{L}$ for TD controls; $P=0.48)$. Additional information regarding the unadjusted and adjusted mean BMC is shown in Table 4. This was also true for the CLR analysis that compared the adjusted odds of ASD among children having BMC in the second, third, and fourth quartiles with that of children in the lowest quartile [Adjusted odds ratio $(\mathrm{AOR})=3.82 ; 95 \% \mathrm{CI}, 0.67-21.91 ; \mathrm{AOR}=1.48 ; 95 \% \mathrm{CI}$, 0.35-6.27; and $\mathrm{AOR}=2.43$; 95\% CI, 0.43-13.59, respectively]. Additional details regarding unadjusted and adjusted MOR are provided in Table 5.

\section{Discussion}

\section{Blood manganese concentrations and ASD}

Our results do not indicate a relationship between postnatal BMC and ASD case status of Jamaican children ages 2-8 years. This lack of association between ASD status and BMC was observed in both univariable $(10.9 \mu \mathrm{g} / \mathrm{L}$ in ASD cases vs. $10.5 \mu \mathrm{g} / \mathrm{L}$ in TD controls, $P=0.29)$ and multivariable $(11.5 \mu \mathrm{g} / \mathrm{L}$ in ASD cases vs. $11.9 \mu \mathrm{g} / \mathrm{L}$ in TD controls, $P=0.48$ ) analyses that controlled for potential confounding effects of paternal age, parental education levels, place of child's birth (Kingston parish vs. other parishes), consumption of root vegetables ("yam, sweet potato, or dasheen"), "cabbage", salt water fish, and cakes/buns. Our findings from univariable and multivariable CLR analyses also did not suggest any significant associations between BMC analyzed as a categorical variable and ASD (both p-values based on Wald's chi-square test with 3 degrees of freedom $>0.25$ ). Specifically, compared with children having BMC in the lowest quartile, all of the $95 \%$ CIs for adjusted odds ratios of ASD among children having BMC in the second, third, and fourth quartiles contained $1[\mathrm{AOR}=3.82 ; 95 \% \mathrm{CI}$, 0.67-21.91; $\mathrm{AOR}=1.48$; 95\% CI, 0.35-6.27; and $\mathrm{AOR}=2.43$; 95\% CI, 0.43-13.59, respectively]. Our findings indicate a lack of significant association between postnatal BMC and ASD, regardless of whether BMC is analyzed as a continuous or a categorical (i.e., 4 quartiles) variable.

To our knowledge, there are no previous studies using venous whole blood samples as a biomarker for manganese exposure in children with ASD, but our findings are consistent with results for manganese exposures measured using other methods. For example, a study from Canada reported similar mean red blood cell manganese concentrations in ASD cases and age-matched TD controls [407.4 $\mathrm{nmol} / \mathrm{L}(22.4 \mu \mathrm{g} / \mathrm{L})$ in ASD cases and $417.6 \mathrm{nmol} / \mathrm{L}$ $(22.9 \mu \mathrm{g} / \mathrm{L})$ in TD controls, $P=0.4)$ ] [46]. Additionally, our results are consistent with those of Windham et al. [39] from San Francisco, California in which the adjusted odds of ASD were not significantly different for children with greater exposure to manganese in ambient air, when adjusted for maternal age, education, and race of the child $(\mathrm{AOR}=1.09$; 95\% CI, 0.75-1.59) and compared with controls [39]. Furthermore, a study of children with ASD and their age- and sex-matched TD controls in Saudi Arabia also reported no significant association between ASD status and manganese levels in hair $(0.38 \mathrm{mg} / \mathrm{kg}$ in ASD cases and $0.41 \mathrm{mg} / \mathrm{kg}$ in TD controls, $P=0.71)$ or urine $(7.32 \mathrm{mcg} / \mathrm{g}$ in ASD cases and $4.81 \mathrm{mcg} / \mathrm{g}$ in TD controls, $P=0.13$ ) [44]. Although the aforementioned studies adjusted for some potential confounding factors, none adjusted for potential dietary confounding factors. On the other hand, our findings are in contrast with those of Abdullah et al. [40] who reported a lower (though marginally significant) level of postnatal manganese in the deciduous teeth of ASD cases compared to TD controls (1.87 ppm in cases vs. $2.91 \mathrm{ppm}$ in controls, $P=0.08$ ) [40]. Another study of children in Saudi Arabia reported significantly lower levels of manganese in hair of children with ASD compared to TD children [42] with no adjustment for potential dietary confounding factors. Nonetheless, we acknowledge that our biomarker, venous whole blood samples, and method of exposure assessment differ from each of the previously reported studies.

Because manganese is naturally present in all human tissues and there are a variety of factors that can influence the levels of manganese in biological samples, such as food and supplemental intake, the usefulness of biomarkers for assessment of cumulative exposure to manganese has been debated [36]. Though there are various 
Table 3 Factors associated with blood manganese concentrations (BMC) by ASD case status and combined samples using General Linear Model (GLM) for all participants (218 children or 109 pairs)

\begin{tabular}{|c|c|c|c|c|c|c|c|c|c|}
\hline \multirow[t]{4}{*}{ Exposure variables } & \multirow{4}{*}{\multicolumn{2}{|c|}{ Category }} & \multicolumn{6}{|c|}{ t-test } & \multirow{4}{*}{$\begin{array}{c}\text { Univariable } \\
\text { analysis GLM } \\
P_{\text {-value }}^{* * *}\end{array}$} \\
\hline & & & \multicolumn{3}{|c|}{ ASD cases } & \multicolumn{3}{|c|}{ TD Controls } & \\
\hline & & & \multicolumn{2}{|c|}{ Mean BMC (SD) $(\mu \mathrm{g} / \mathrm{L})$} & \multirow[t]{2}{*}{$P$-value } & \multicolumn{2}{|c|}{ Mean BMC (SD) $(\mu \mathrm{g} / \mathrm{L})$} & \multirow[t]{2}{*}{$P$-value } & \\
\hline & & & Yes $^{*}$ & $\mathrm{No}^{* *}$ & & Yes $^{*}$ & $\mathrm{No}^{* *}$ & & \\
\hline Age of Child & \multicolumn{2}{|l|}{ More than 4 years } & $10.8(2.8)$ & $11.1(3.2)$ & 0.64 & $10.2(2.4)$ & $12.0(3.4)$ & 0.01 & 0.29 \\
\hline Sex of Child & \multicolumn{2}{|l|}{ Male } & $10.8(2.9)$ & $11.2(3.1)$ & 0.58 & $10.4(2.5)$ & $11.1(3.4)$ & 0.32 & 0.29 \\
\hline Place of child's birth & \multicolumn{2}{|l|}{ Kingston parish } & $11.7(2.5)$ & $10.7(2.9)$ & 0.31 & $10.3(2.7)$ & $10.8(2.8)$ & 0.43 & 0.71 \\
\hline Paternal age (at child's birth) & \multicolumn{2}{|c|}{ More than 35 years } & $10.8(2.7)$ & $10.8(3.10)$ & 0.97 & $11.0(3.5)$ & $10.3(2.4)$ & 0.24 & 0.02 \\
\hline Maternal age & \multirow{2}{*}{\multicolumn{2}{|c|}{ More than 35 years }} & $11.0(3.1)$ & $10.9(2.8)$ & 0.85 & $9.9(1.6)$ & $10.6(2.8)$ & 0.45 & 0.53 \\
\hline (at child's birth) & & & & & & & & & \\
\hline Parental education levels & \multirow{2}{*}{\multicolumn{2}{|c|}{ At least one of the parents had education beyond high school }} & $10.5(2.8)$ & $11.6(3.0)$ & 0.06 & $10.7(3.0)$ & $10.3(2.4)$ & 0.38 & 0.82 \\
\hline (at child's birth) & & & & & & & & & \\
\hline Source of drinking water & \multicolumn{2}{|l|}{ Piped water } & $10.8(2.9)$ & $11.8(1.5)$ & 0.43 & $10.6(2.7)$ & $8.6(1.6)$ & 0.14 & 0.33 \\
\hline Source of cooking water & \multicolumn{2}{|l|}{ Piped water } & $10.8(2.9)$ & $11.8(1.5)$ & 0.43 & $10.6(2.7)$ & $8.6(1.6)$ & 0.14 & 0.37 \\
\hline \multirow[t]{11}{*}{ Fruits and vegetables consumption } & \multirow[t]{2}{*}{ Root vegetables } & A. Yam, sweet potato, or dasheen & $10.9(2.9)$ & $10.9(3.3)$ & 0.89 & $10.3(2.6)$ & $11.1(3.2)$ & 0.28 & 0.06 \\
\hline & & B. Carrot or pumpkin & $10.9(3.0)$ & $10.7(2.3)$ & 0.81 & $10.5(2.7)$ & $10.5(2.10)$ & 0.99 & 0.66 \\
\hline & \multirow[t]{3}{*}{ Leafy vegetables } & A. Lettuce & $11.1(3.0)$ & $10.7(2.8)$ & 0.49 & $10.3(2.3)$ & $10.6(3.2)$ & 0.67 & 0.94 \\
\hline & & B. Callaloo, broccoli, or pakchoi & $10.9(3.0)$ & $10.9(2.7)$ & 0.91 & $10.5(2.7)$ & $10.5(3.0)$ & 0.96 & 0.99 \\
\hline & & C. Cabbage & $10.7(2.7)$ & $11.3(3.1)$ & 0.26 & $10.4(2.7)$ & $11.1(2.1)$ & 0.49 & 0.14 \\
\hline & Legumes & String beans & $11.1(3.2)$ & $10.8(2.7)$ & 0.66 & $10.1(2.3)$ & $10.7(2.9)$ & 0.23 & 0.32 \\
\hline & \multirow[t]{5}{*}{ Fruits } & Tomatoes & $11.1(2.9)$ & $10.5(2.8)$ & 0.24 & $10.4(2.5)$ & $11.1(3.4)$ & 0.38 & 0.82 \\
\hline & & Ackee & $10.8(2.7)$ & $11.1(3.1)$ & 0.59 & $10.5(2.7)$ & $9.9(2.1)$ & 0.51 & 0.89 \\
\hline & & Avocado & $11.1(2.1)$ & $10.8(3.1)$ & 0.60 & $10.5(2.7)$ & $10.5(2.6)$ & 0.94 & 0.80 \\
\hline & & Green banana & $10.8(3.0)$ & $11.0(2.6)$ & 0.83 & $10.5(2.8)$ & $9.8(1.8)$ & 0.44 & 0.31 \\
\hline & & Fried plantains & $11.1(2.7)$ & $10.4(3.3)$ & 0.29 & $10.5(2.7)$ & $9.8(2.7)$ & 0.39 & 0.55 \\
\hline \multirow[t]{8}{*}{ Seafood consumption } & \multicolumn{2}{|c|}{ High seafood consumption (More than 6 meals per week) } & $10.9(2.8)$ & $10.9(2.9)$ & 0.97 & $10.8(2.7)$ & $10.2(2.7)$ & 0.24 & 0.63 \\
\hline & \multicolumn{2}{|l|}{ Ate salt water fish } & $11.1(3.0)$ & $10.2(2.2)$ & 0.17 & $10.5(2.7)$ & $10.2(2.4)$ & 0.75 & 0.09 \\
\hline & \multicolumn{2}{|c|}{ Ate fresh water fish (Pond fish, tilapia) } & $10.9(2.6)$ & $10.9(3.1)$ & 0.90 & $11.0(2.8)$ & $9.9(2.5)$ & 0.03 & 0.54 \\
\hline & \multicolumn{2}{|c|}{ Ate sardine, mackerel (Canned fish) } & $10.9(3.0)$ & $11.0(2.7)$ & 0.86 & $10.5(2.7)$ & $10.5(2.8)$ & 0.98 & 0.75 \\
\hline & \multicolumn{2}{|c|}{ Ate tuna (Canned fish) } & $11.0(3.4)$ & $10.8(2.6)$ & 0.85 & $10.5(2.9)$ & $10.5(2.6)$ & 0.99 & 0.82 \\
\hline & Ate salt fish (Pickl & ckerel) & $10.8(3.0)$ & $11.0(2.6)$ & 0.77 & $10.7(2.7)$ & $8.9(1.8)$ & 0.054 & 0.94 \\
\hline & Ate shellfish (Lobs & rabs) & $11.5(2.3)$ & $10.8(2.9)$ & 0.57 & $10.7(2.2)$ & $10.5(2.8)$ & 0.82 & 0.88 \\
\hline & Ate shrimp & & $11.0(3.6)$ & $10.9(2.7)$ & 0.83 & $11.1(2.5)$ & $10.3(2.8)$ & 0.25 & 0.58 \\
\hline
\end{tabular}


Table 3 Factors associated with blood manganese concentrations (BMC) by ASD case status and combined samples using General Linear Model (GLM) for all participants ( 218 children or 109 pairs) (Continued)

\begin{tabular}{|c|c|c|c|c|c|c|c|c|}
\hline \multirow[t]{8}{*}{ Grain consumption } & Rice & $10.8(2.8)$ & $12.8(5.4)$ & 0.25 & $10.5(2.7)$ & $N R^{\circledast}$ & $N R^{\circledast}$ & 0.27 \\
\hline & Fried dumpling & $11.0(2.8)$ & $10.6(3.2)$ & 0.63 & $10.5(2.7)$ & $9.9(3.0)$ & 0.50 & 0.30 \\
\hline & Boiled dumpling & $11.1(3.0)$ & $10.7(2.6)$ & 0.61 & $10.6(2.7)$ & $7.6(1.1)$ & 0.12 & 0.64 \\
\hline & White bread & $10.8(2.6)$ & $10.9(3.2)$ & 0.85 & $10.6(2.8)$ & $10.0(2.5)$ & 0.34 & 0.93 \\
\hline & Whole wheat bread & $10.8(3.0)$ & $11.0(2.7)$ & 0.80 & $10.1(2.5)$ & $11.1(2.9)$ & 0.09 & 0.34 \\
\hline & Cakes/buns & $10.7(2.8)$ & $11.7(3.2)$ & 0.21 & $10.8(2.7)$ & $9.6(3.4)$ & 0.65 & 0.20 \\
\hline & Porridge (cornmeal, oatmeal) & $10.9(3.0)$ & $11.0(2.5)$ & 0.82 & $10.5(2.7)$ & $9.5(0.8)$ & 0.54 & 0.60 \\
\hline & Cereal & $10.6(2.5)$ & $11.8(3.7)$ & 0.053 & $10.5(2.7)$ & $9.5(3.8)$ & 0.29 & 0.49 \\
\hline
\end{tabular}

"The "Yes" column includes subjects who met the category specified in front of each exposure variable.
"The "No" column includes subjects who did not meet the category specified in front of each exposure variable.

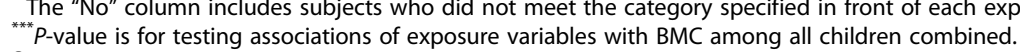

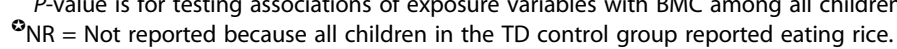

Note: All missing data are the same as those reported in the footnote of Table 2. 
Table 4 Unadjusted and adjusted mean blood manganese concentrations (BMC) by ASD cases status based on GLMs and 109 1:1 matched pairs

\begin{tabular}{llll}
\hline & $\begin{array}{l}\text { Mean BMC (SD) } \\
\text { ASD Cases }(\boldsymbol{\mu g} / \mathbf{L})\end{array}$ & $\begin{array}{l}\text { Mean BMC (SD) } \\
\text { TD Controls }(\boldsymbol{\mu g} / \mathbf{L})\end{array}$ & $\boldsymbol{P}$-value \\
\hline Unadjusted & $10.9(2.9)$ & $10.5(2.7)$ & 0.29 \\
Adjusted $^{\boldsymbol{a}}$ & $11.5(2.7)^{*}$ & $11.9(2.7)^{*}$ & 0.48
\end{tabular}

${ }^{a}$ Factors adjusted for include: paternal age, parental education, place of child's birth (Kingston parish vs. other parishes), consumption of root vegetables ("yam, sweet potato, or dasheen"), "cabbage", salt water fish, and cakes/buns. *Standard deviation (SD) for adjusted model equals square root of means squared error in the final multivariable GLM.

potential biomarkers for measurement of manganese exposure, blood and urine have been frequently used to assess exposure in occupational setting [36]. Although manganese is naturally found at some level in all human hair, the potential for external exposure to manganese through air contamination and dust may overestimate concentrations measured using hair as a marker of exposure [36]. Manganese can also accumulate in bone and teeth [36], but differences in techniques for sampling and assessment of levels may influence results [40]. Though blood may not be a good indicator of exposure via inhalation [61], it is considered as an adequate indicator for dietary intake [62]. For this reason, we believe our results are more indicative of the influence of orally ingested manganese on ASD case status.

\section{Blood manganese concentration in Jamaican children}

To our knowledge, there are no previously published reports on blood, hair, or urine manganese levels in Jamaican children. The mean BMC for our sample of Jamaican TD children was $10.5 \mu \mathrm{g} / \mathrm{L}(\mathrm{SD}=2.70 \mu \mathrm{g} / \mathrm{L})$, which is lower than levels reported in other less developed countries. For

Table 5 Unadjusted and adjusted matched odds ratios (MOR) for assessing associations between ASD status and quartiles of blood manganese concentrations (BMC) based on the CLR models for 109 ASD cases and their 1:1 matched TD controls

\begin{tabular}{lllll}
\hline & Quartile & $\mathbf{n}$ & MOR $(95 \% \mathrm{Cl})$ & P-value \\
\hline Unadjusted & Q1 $(1 \mu \mathrm{g} / \mathrm{L}-8.9 \mu \mathrm{g} / \mathrm{L})$ & 56 & Ref. & - \\
& Q2 $(9.0 \mu \mathrm{g} / \mathrm{L}-10.0 \mu \mathrm{g} / \mathrm{L})$ & 64 & $0.71(0.32,1.61)$ & 0.42 \\
& Q3 $(10.0 \mu \mathrm{g} / \mathrm{L}-12.0 \mu \mathrm{g} / \mathrm{L})$ & 54 & $1.05(0.46,2.40)$ & 0.91 \\
& Q4 $(>12 . \mu \mathrm{g} / \mathrm{L})$ & 44 & $0.49(0.21,1.15)$ & 0.10 \\
Adjusted $^{a}$ & Q1 $(1 \mu \mathrm{g} / \mathrm{L}-8.9 \mu \mathrm{g} / \mathrm{L})$ & 56 & Ref. & - \\
& Q2 $(9.0 \mu \mathrm{g} / \mathrm{L}-10.0 \mu \mathrm{g} / \mathrm{L})$ & 64 & $3.82(0.67,21.91)$ & 0.13 \\
& Q3 $(10.0 \mu \mathrm{g} / \mathrm{L}-12.0 \mu \mathrm{g} / \mathrm{L})$ & 54 & $1.48(0.35,6.27)$ & 0.60 \\
& Q4 $(>12.0 \mu \mathrm{g} / \mathrm{L})$ & 44 & $2.43(0.43,13.59)$ & 0.31 \\
\hline
\end{tabular}

${ }^{a}$ Factors adjusted for include: paternal age, parental education, place of child's birth (Kingston parish vs. other parishes), consumption of root vegetables ("yam, sweet potato, or dasheen"), "cabbage", salt water fish, and cakes/buns. Ref. $=$ Referent category for all matched odds ratios is the lowest quartile of blood manganese concentrations. example, the mean BMC for 303 children ages 8 to 11 years enrolled in the Health Effects of Arsenic Longitudinal Study (HEALS) in Araihazar, Bangladesh was $14.78 \mu \mathrm{g} / \mathrm{L}$ $(\mathrm{SD}=3.72 \mu \mathrm{g} / \mathrm{L})$ [18], while the mean BMC for male and female controls ages 3 to 7 years in a study from Pakistan were $29.5 \mu \mathrm{g} / \mathrm{L}(\mathrm{SD}=7.5 \mu \mathrm{g} / \mathrm{L})$ and $31.2 \mu \mathrm{g} / \mathrm{L}$ $(\mathrm{SD}=5.3 \mu \mathrm{g} / \mathrm{L})$, respectively [63]. On the other hand, the mean BMC of our sample was similar to that reported from studies in emerging countries, such as South Africa, where the mean BMC in a study of children ages 9 to 13 years in Durban, South Africa was $10.1 \mu \mathrm{g} / \mathrm{L}$ $(\mathrm{SD}=3.4 \mu \mathrm{g} / \mathrm{L})[64]$ and was $9.80 \mu \mathrm{g} / \mathrm{L}(\mathrm{SD}=3.59 \mu \mathrm{g} / \mathrm{L})$ in first graders enrolled in a separate study in Johannesburg, South Africa [65]. Reported mean BMC from more developed countries are close to that of our sample. For example, mean BMC for 57 female and 56 male children ages $0.29-2.4$ years in Sydney, Australia, were $12.3 \mu \mathrm{g} / \mathrm{L}$ $(\mathrm{SD}=4.8 \mu \mathrm{g} / \mathrm{L})$ and $12.2 \mu \mathrm{g} / \mathrm{L}(\mathrm{SD}=6.0 \mu \mathrm{g} / \mathrm{L})$, respectively [66], while the mean BMC for 38 children ages 7-9 years from the Community Actively Researching Exposure Study (CARES) in Marietta, Ohio, was $9.5 \mu \mathrm{g} / \mathrm{L}(\mathrm{SD}=2.4 \mu \mathrm{g} / \mathrm{L}$ ) [67]. In September 2013, the Centers for Disease Control and Prevention (CDC) published data from NHANES 2011-2012 reporting that manganese concentrations ranged from $1.61 \mu \mathrm{g} / \mathrm{L}$ to $62.51 \mu \mathrm{g} / \mathrm{L}$ for individuals who participated in this study with ages ranging from 1 to 80 years [68]. A subgroup analysis of these publicly available data revealed a mean $\mathrm{BMC}$ of $10.7 \mu \mathrm{g} / \mathrm{L}(\mathrm{SD}=6.98 \mu \mathrm{g} / \mathrm{L})$ for children between $2-8$ years living in the US. Our findings indicate that BMC in TD Jamaican children are similar to those of the developed countries and much lower than those reported from some of the aforementioned developing countries.

Although the mean BMC in Jamaican children are similar to those of children living in the US, it is important to emphasize that higher levels of manganese have been shown to have adverse effects on cognitive [13] and neuromuscular function [12] in adults. More alarming are the adverse events seen in children exposed to excessive manganese including increased behavioral problems [14,15], reduced verbal and full-scale IQ [17-21]. In particular, Takser et al. [22] assessed psychomotor development of children in three different age groups ( 9 months, 3 years, and 6 years). They showed a relationship between high cord BMC and decreased attention in children 3 years of age (partial correlation $r=-0.33, P<0.001$ ) after adjustment for potential confounding including child's gender and mother's educational level [22]. A study in 1-year old children from Mexico City reported an inverted U-shaped association between BMC and neurodevelopment, with lower Mental Development Index scores found for children in the lowest and the highest quintiles compared with children in the middle three quintiles after adjustment for several potential 
confounding variables [25]. Considering the potential for numerous adverse outcomes related to excessive manganese exposure, in the following we discuss factors associated with BMC in TD Jamaican children.

\section{Age and sex of children and their association with blood manganese concentrations}

It has been reported that BMC declines with age [69-73]. For example, Claus Henn et al. [73] reported mean BMC of $24.7 \mu \mathrm{g} / \mathrm{L}$ and $21.5 \mu \mathrm{g} / \mathrm{L}$ for Mexican children at age 12 months and 24 months, respectively [73] and it has been shown that this decline in BMC over time is statistically significant $[\beta=-5.7 ; 95 \% \mathrm{CI}:-6.2$ to -5.1$]$ [26]. Our findings indicated that TD Jamaican children older than 4 years have a significantly lower mean $\mathrm{BMC}$ than children whose age was between $2-4$ years, $(10.2 \mu \mathrm{g} / \mathrm{L}$ vs. $12.0 \mu \mathrm{g} / \mathrm{L}, P=0.01)$. This finding is consistent with evidence of an inverse association between manganese and age [69-73]. This finding along with the information reported in the literature suggests that age could be a potential confounder when an association between BMC and ASD is investigated. We also did not find sex differences for BMC in our sample. These results are consistent with those of Clause Henn et al. [73] who also reported no sex differences in BMC. Additionally, a study in TD Pakistani children age 3 to 7 years reported a mean $\mathrm{BMC}$ of $29.5 \mu \mathrm{g} / \mathrm{L}(\mathrm{SD}=7.5 \mu \mathrm{g} / \mathrm{L})$ in 104 boys and $31.2 \mu \mathrm{g} / \mathrm{L}(\mathrm{SD}=5.3 \mu \mathrm{g} / \mathrm{L})$ in 106 girls [63]; although a formal comparison by sex is not reported in this paper, our calculation of a z-score for the mean difference based on the summary data reported resulted in $\mathrm{Z}=1.89$ with a two-side p-value of 0.07 , suggesting a borderline, but not significant, association between sex and BMC. In our study since we matched ASD cases and TD controls by age and sex in the study design phase, we did not include age and sex in our multivariable models that investigated the possible association between BMC and ASD.

Seafood consumption and blood manganese concentrations Residents of islands often consume larger amounts of seafood compared to those living in other habitats. Through contaminated water, manganese can accumulate in tissues of fish and other sea creatures [32-34,74,75]. Manganese seems to accumulate in certain fish species with considerable biological significance [75]. For example, Kumar et al. [76] reported that manganese levels in aquaculture ponds fish were 2.4 times higher than in coastal water fish. Our analysis indicated that TD children who ate fresh water fish (pond fish, tilapia) had a higher BMC than children who did not $(11.0 \mu \mathrm{g} / \mathrm{L}$ vs. $9.9 \mu \mathrm{g} / \mathrm{L} ; P=0.03)$. Considering that results from a study of heavy metal concentrations in seafood purchased in a coastal community in Canada showed that metal concentrations, including manganese, in locally caught seafood products were higher than that observed in imported products [34] and another in New
Jersey reported correlations between manganese concentrations in certain seafood products (fish tissue) [74] these findings are not surprising. Though the risks and benefits of eating fish and seafood have been debated, especially concerning exposure to heavy metals [77,78], our results indicate that there is a significant increased risk of manganese exposure via fish consumption in Jamaican children.

\section{Limitations}

Since potential ASD cases in the UWI Jamaica Autism Database are referred from all over the island and TD controls were more likely to be from the Kingston area, a higher number of the TD controls are born in Kingston parish than the ASD cases. Therefore, manganese concentrations from our TD controls may not be generalizable to all children in Jamaica. In future studies it will be important to sample TD controls more widely from the island. Furthermore, although we used a culturally sensitive food frequency questionnaire that had been previously utilized in Jamaica, there is potential for recall bias from respondents. Although we used blood manganese concentrations as our biomarker of exposure, we acknowledge that tissue markers of exposure, such as nervous tissue, may be better indicators of long term exposures. Though prior studies have indicated that hair manganese levels increase over years of exposure, these measurements may be influenced by external exposures as well [79]. Considering that the best biomarker of manganese exposures is still not established, we used blood manganese concentration, which is considered as an adequate biomarker for body burden [79,80]. Our data collection method also could not account for timing of manganese exposure via food consumption, so responses may only represent recent exposures. In addition, our BMC data were not differentiated by type of manganese exposures (i.e., organic and inorganic), so we could not provide any discussion regarding this distinction based on our data. In addition, it is important to note that BMC measurements for children represent "current" exposure, implying that the manganese exposure for ASD cases reflect BMC after the child is already diagnosed with ASD. While we did not observe a relationship between blood manganese concentrations and ASD status, we acknowledge that it is possible that prenatal or early life exposures may be more predictive of ASD. We also lack information on maternal diet or manganese levels during pregnancy. Although we did not find differences in BMC for children with ASD versus TD controls, there may have been genetic differences in susceptibility to manganese exposure. Palmer et al. [81] suggested that without attention to gene-environment interaction, results of tests for safety of environmental exposures, such as manganese, should not be interpreted as confirmatory [81]. Despite our initial effort to keep the age of matched TD control children within six months of ASD cases, for $12.8 \%$ of 
pairs the age of the TD controls was within 7-15 months. However, we do not believe this difference would be likely to have any significant impact on the findings reported here.

\section{Conclusions}

Our study results found no statistically significant association between BMC and ASD status. To our knowledge, we are the first to report no association between blood manganese concentrations and ASD in children, while controlling for dietary confounding factors. Furthermore, this is the first study to report blood manganese levels of children residing in Jamaica. Our findings demonstrated that BMC for children in Jamaica were lower than that of less developed countries and similar to that of more developed countries.

\section{Competing interests}

The authors declare that they have no competing interests.

\section{Authors' contributions}

MHR, MSV, KAL, JB, and EB have made substantial contributions to conception and study design; MSV and SSP contributed to acquisition of data; MAH, SSP, MSV, MLG, and MHR have made contributions to data quality assurance procedures; MHR, ASD, and MAH conducted data analysis; MHR, ASD, MAH, MSV, and JB have contributed to interpretation of data; MHR, ASD, and MAH significantly contributed to drafting of the manuscript, and MHR, KAL, MSV, MLG, DAP, JB and EB provided critical revision of the manuscript; All authors have read and approved the final version submitted for publication.

\section{Acknowledgements}

This research is co-funded by the Eunice Kennedy Shriver National Institute of Child Health and Human Development (NICHD) and the National Institutes of Health Fogarty International Center (NIH-FIC) by a grant [R21HD057808] as well as National Institute of Environmental Health Sciences (NIEHS) by a grant [R01ES022165] awarded to University of Texas Health Science Center at Houston. We also acknowledge the support provided by the Biostatistics/ Epidemiology/ Research Design (BERD) component of the Center for Clinical and Translational Sciences (CCTS) for this project. CCTS is mainly funded by the NIH Centers for Translational Science Award (NIH CTSA) grant (UL1 RR024148), awarded to University of Texas Health Science Center at Houston in 2006 by the National Center for Research Resources (NCRR) and its renewal (UL1 TR000371) by the National Center for Advancing Translational Sciences (NCATS). The content is solely the responsibility of the authors and does not necessarily represent the official views of the NICHD or the $\mathrm{NIH}-\mathrm{FIC}$ or NIEHS or the NCRR or the NCATS.

\section{Author details}

${ }^{1}$ Division of Epidemiology, Human Genetics, and Environmental Sciences (EHGES), University of Texas School of Public Health at Houston, Houston, Texas, USA. ${ }^{2}$ Division of Clinical and Translational Sciences, Department of Internal Medicine, University of Texas Medical School at Houston, Houston, Texas 77030, USA. ${ }^{3}$ Biostatistics/Epidemiology/Research Design (BERD) component, Center for Clinical and Translational Sciences (CCTS), University of Texas Health Science Center at Houston, UT Professional Building Suite 1100.05, 6410 Fannin Street, Houston, TX 77030, USA. ${ }^{4}$ Department of Child \& Adolescent Health, The University of the West Indies (UWI), Mona Campus, Kingston, Jamaica. ${ }^{5}$ Department of Psychiatry and Behavioral Sciences, University of Texas Medical School at Houston, Houston, Texas 77054, USA. ${ }^{6}$ Human Genetics Center, School of Public Health, University of Texas Health Science Center at Houston, Houston, Texas 77030, USA.

Received: 3 April 2014 Accepted: 7 August 2014

Published: 23 August 2014

\section{References}

1. Genuis SJ: Is autism reversible? Acta Paediatr 2009, 98:1575-1578.

2. Volkmar FR, Chawarska K: Autism in infants: an update. World Psychiatr 2008, 7:19-21.
3. Gillberg C: How Severe is Autism - Really? The International Meeting fo Autism Research (IMFAR), 12th Annual Meeting May 2-4, 2013. Donostia, San Sebastián Basque, Spain: 2013.

4. Kumar RA, Christian SL: Genetics of autism spectrum disorders. Curr Neurol Neurosci Rep 2009, 9:188-197.

5. Geschwind DH: Advances in Autism: Genetics Filling the Empty Fortress. The International Meeting for Autism Research (IMFAR), 12th Annual Meeting May 2-4, 2013. Donostia,San Sebastián Basque, Spain: 2013.

6. Gardener H, Spiegelman D, Buka SL: Perinatal and neonatal risk factors for autism: a comprehensive meta-analysis. Pediatrics 2011, 128:344-355.

7. Hertz-Picciotto l: The Role of Environmental Exposures in Autism Etiology: A Retrospective of the Last Decade, New Results and Frontiers for the Future. The International Meeting for Autism Research (IMFAR), 12th Annual Meeting May 2-4, 2013. Donostia,San Sebastián Basque, Spain: 2013.

8. Volk HE, Lurmann F, Penfold B, Hertz-Picciotto I, McConnell R: Traffic-related air pollution, particulate matter, and autism. JAMA Psychiatry 2013, 70:71-77.

9. Hallmayer J, Cleveland S, Torres A, Phillips J, Cohen B, Torigoe T, Miller J, Fedele A, Collins J, Smith K, Lotspeich L, Croen LA, Ozonoff S, Lajonchere C, Grether JK, Risch N: Genetic heritability and shared environmental factors among twin pairs with autism. Arch Gen Psychiatry 2011, 68:1095-1102.

10. Landrigan PJ, Lambertini L, Birnbaum LS: A research strategy to discover the environmental causes of autism and neurodevelopmental disabilities. Environ Health Perspect 2012, 120:a258-a260.

11. Environmental Protection Agency (EPA): Manganese Toxicity and Exposure Assessment for Children's Health (TEACH) Chemical Summary. United States Environmental Protection Agency; 2007. http://www.epa.gov/teach/ chem_summ/manganese_summary.pdf.

12. Agency for Toxic Substances and Disease Registry (ATSDR): Toxicological profile for Manganese. Atlanta, GA: Agency for Toxic Substances and Disease Registry (ATSDR); 2012. http://www.atsdr.cdc.gov/toxprofiles/tp.asp? $i d=102 \&$ tid $=23$.

13. Zoni S, Albini E, Lucchini R: Neuropsychological testing for the assessment of manganese neurotoxicity: a review and a proposal. Am J Ind Med 2007, 50:812-830.

14. Bouchard M, Laforest F, Vandelac L, Bellinger D, Mergler D: Hair manganese and hyperactive behaviors: pilot study of school-age children exposed through tap water. Environ Health Perspect 2007, 115:122-127.

15. Ericson JE, Crinella FM, Clarke-Stewart KA, Allhusen VD, Chan T, Robertson RT: Prenatal manganese levels linked to childhood behavioral disinhibition. Neurotoxicol Teratol 2007, 29:181-187.

16. Khan K, Factor-Litvak P, Wasserman GA, Liu X, Ahmed E, Parvez F, Slavkovich V, Levy D, Mey J, van Geen A, Graziano JH: Manganese exposure from drinking water and children's classroom behavior in Bangladesh. Environ Health Perspect 2011, 119:1501-1506.

17. Wright RO, Amarasiriwardena C, Woolf AD, Jim R, Bellinger DC: Neuropsychological correlates of hair arsenic, manganese, and cadmium levels in school-age children residing near a hazardous waste site. Neurotoxicology 2006, 27:210-216.

18. Wasserman GA, Liu X, Parvez F, Factor-Litvak P, Ahsan H, Levy D, Kline J, van Geen A, Mey J, Slavkovich V, Siddique AB, Islam T, Graziano JH: Arsenic and manganese exposure and children's intellectual function. Neurotoxicology 2011, 32:450-457.

19. Kim Y, Kim BN, Hong YC, Shin MS, Yoo HJ, Kim JW, Bhang SY, Cho SC: Co-exposure to environmental lead and manganese affects the intelligence of school-aged children. Neurotoxicology 2009, 30:564-571.

20. Menezes-Filho JA, Novaes CO, Moreira JC, Sarcinelli PN, Mergler D: Elevated manganese and cognitive performance in school-aged children and their mothers. Environ Res 2011, 111:156-163.

21. Bouchard MF, Sauve S, Barbeau B, Legrand M, Brodeur ME, Bouffard T, Limoges E, Bellinger DC, Mergler D: Intellectual impairment in school-age children exposed to manganese from drinking water. Environ Health Perspect 2011, 119:138-143.

22. Takser L, Mergler D, Hellier G, Sahuquillo J, Huel G: Manganese, monoamine metabolite levels at birth, and child psychomotor development. Neurotoxicology 2003, 24:667-674.

23. Khan K, Wasserman GA, Liu X, Ahmed E, Parvez F, Slavkovich V, Levy D, Mey J, van Geen A, Graziano JH, Factor-Litvak P: Manganese exposure from drinking water and children's academic achievement. Neurotoxicology 2012, 33:91-97.

24. Bhang SY, Cho SC, Kim JW, Hong YC, Shin MS, Yoo HJ, Cho IH, Kim Y, Kim BN: Relationship between blood manganese levels and children's 
attention, cognition, behavior, and academic performance-A nationwide cross-sectional study. Environ Res 2013, 126:9-16.

25. Claus Henn B, Ettinger AS, Schwartz J, Tellez-Rojo MM, Lamadrid-Figueroa $H$, Hernandez-Avila M, Schnaas L, Amarasiriwardena C, Bellinger DC, Hu H, Wright RO: Early postnatal blood manganese levels and children's neurodevelopment. Epidemiology 2010, 21:433-439.

26. Roels HA, Bowler RM, Kim Y, Claus HB, Mergler D, Hoet P, Gocheva W, Bellinger DC, Wright RO, Harris MG, Chang Y, Bouchard MF, Riojas-Rodriguez $\mathrm{H}$, Menezes-Filho JA, Tellez-Rojo MM: Manganese exposure and cognitive deficits: a growing concern for manganese neurotoxicity. Neurotoxicology 2012, 33:872-880.

27. Bounds S: Manganese and Its Inorganic Compounds: 1. Toxicokinetic Aspects. In Regulation (EC) No. 1907/2006. 8-31-2009. Manganese REACH Administration (MARA). A Toxicokinetic Assessment for the Registration, Evaluation and Authorisation of Chemicals, Regulation (REACH). http://reach.treatdev.com/ Toxicokinetics.pdf.

28. Boyes WK: Essentiality, toxicity, and uncertainty in the risk assessment of manganese. J Toxicol Environ Health A 2010, 73:159-165.

29. Lalor G: Geochemical mapping in Jamaica. Environ Geochem Health 1996, 18:89-97.

30. Nduka JK, Orisakwe OE, Ezenweke LO, Chendo MN, Ezenwa TE: Heavy metal contamination of foods by refuse dump sites in Awka, southeastern Nigeria. Sci World J 2008, 8:941-948.

31. Howe A, Fung LH, Lalor G, Rattray R, Vutchkov M: Elemental composition of Jamaican foods 1: a survey of five food crop categories. Environ Geochem Health 2005, 27:19-30.

32. Turan C, Dural M, Oksuz A, Ozturk B: Levels of heavy metals in some commercial fish species captured from the Black Sea and Mediterranean coast of Turkey. Bull Environ Contam Toxicol 2009, 82:601-604.

33. Ebrahimzadeh MA, Eslami S, Nabavi SF, Nabavi SM: Determination of trace element level in different tissues of the leaping mullet (Liza saliens, Mugilidae) collected from Caspian Sea. Biol Trace Elem Res 2011, 144:804-811.

34. Fraser M, Surette C, Vaillancourt C: Fish and seafood availability in markets in the Baie des Chaleurs region, New Brunswick, Canada: a heavy metal contamination baseline study. Environ Sci Pollut Res Int 2013, 20:761-770.

35. Greger JL: Nutrition versus toxicology of manganese in humans: evaluation of potential biomarkers. Neurotoxicology 1999, 20:205-212.

36. Santamaria $A B$, Sulsky SI: Risk assessment of an essential element: manganese. J Toxicol Environ Health A 2010, 73:128-155.

37. Roth JA: Homeostatic and toxic mechanisms regulating manganese uptake, retention, and elimination. Biol Res 2006, 39:45-57

38. Finley JW, Davis CD: Manganese deficiency and toxicity: are high or low dietary amounts of manganese cause for concern? Biofactors 1999, 10:15-24.

39. Windham GC, Zhang L, Gunier R, Croen LA, Grether JK: Autism spectrum disorders in relation to distribution of hazardous air pollutants in the San Francisco Bay area. Environ Health Perspect 2006, 114:1438-1444.

40. Abdullah MM, Ly AR, Goldberg WA, Clarke-Stewart KA, Dudgeon JV, Mull CG, Chan TJ, Kent EE, Mason AZ, Ericson JE: Heavy metal in children's tooth enamel: related to autism and disruptive behaviors? J Autism Dev Disord 2012, 42:929-936.

41. Adams JB, Holloway CE, George F, Quig D: Analyses of toxic metals and essential minerals in the hair of Arizona children with autism and associated conditions, and their mothers. Biol Trace Elem Res 2006, 110:193-209.

42. Al-Ayadhi LY: Heavy metals and trace elements in hair samples of autistic children in central Saudi Arabia. Neurosciences (Riyadh) 2005, 10:213-218.

43. De Palma G, Catalani S, Franco A, Brighenti M, Apostoli P: Lack of correlation between metallic elements analyzed in hair by ICP-MS and autism. J Autism Dev Disord 2012, 42:342-353.

44. Blaurock-Busch E, Amin OR, Rabah T: Heavy metals and trace elements in hair and urine of a sample of arab children with autistic spectrum disorder. Maedica (Buchar) 2011, 6:247-257.

45. Blaurock-Busch E, Amin OR, Dessoki HH, Rabah T: Toxic Metals and Essential Elements in Hair and Severity of Symptoms among Children with Autism. Maedica (Buchar) 2012, 7:38-48.

46. Jory J, McGinnis WR: Red-cell trace minerals in children with autism. Am J Biochem Biotechnol 2008, 4:101-104.

47. Rahbar MH, Samms-Vaughan M, Loveland KA, Ardjomand-Hessabi M, Chen Z, Bressler J, Shakespeare-Pellington S, Grove ML, Bloom K, Pearson DA, Lalor GC, Boerwinkle E: Seafood Consumption and Blood Mercury
Concentrations in Jamaican Children With and Without Autism Spectrum Disorders. Neurotox Res 2013, 23:22-38.

48. Rahbar MH, Samms-Vaughan M, Loveland KA, Pearson DA, Bressler J, Chen Z, Ardjomand-Hessabi M, Shakespeare-Pellington S, Grove ML, Beecher C, Bloom K, Boerwinkle E: Maternal and paternal age are jointly associated with childhood autism in Jamaica. J Autism Dev Disord 2012, 42:1928-1938.

49. Rahbar MH, Samms-Vaughan M, Ardjomand-Hessabi M, Loveland KA, Dickerson AS, Chen Z, Bressler J, Shakespeare-Pellington S, Grove ML, Bloom K, Wirth J, Pearson DA, Boerwinkle E: The role of drinking water sources, consumption of vegetables and seafood in relation to blood arsenic concentrations of Jamaican children with and without Autism Spectrum Disorders. Sci Total Environ 2012, 433:362-370.

50. Rahbar MH, Samms-Vaughan M, Dickerson AS, Loveland KA, Ardjomand-Hessabi M, Bressler J, Lee M, Shakespeare-Pellington S, Grove ML, Pearson DA, Boerwinkle $E$ : Role of fruits, vegetables, and seafood consumption in blood cadmium concentrations of Jamaican children with and without Autism Spectrum Disorder. Res Autism Spectrum Disord 2014, 8:1134-1145.

51. American Psychiatric Association: Diagnostic and Statistical Manual of Mental Disorders. Text Revision (DSM-IV-TR) Fourth Edition. Washington, DC: American Psychiatric Publishing, Inc; 2000.

52. Schopler E, Reichler RJ, DeVellis RF, Daly K: Toward objective classification of childhood autism: Childhood Autism Rating Scale (CARS). J Autism Dev Disord 1980, 10:91-103.

53. Rutter M, Bailey A, Lord C: The Social Communication Questionnaire. Los Angeles, CA: Western Psychological Services; 2003.

54. Lord C, Rutter M: DiLavore P, Risi S: Autism Diagnostic Observation Schedule (ADOS). Los Angeles, CA: Western Psychological Services; 2002.

55. Lord C, Risi S, Lambrecht L, Cook EH Jr, Leventhal BL, DiLavore PC, Pickles A, Rutter M: The autism diagnostic observation schedule-generic: a standard measure of social and communication deficits associated with the spectrum of autism. J Autism Dev Disord 2000, 30:205-223.

56. Lord C, Pickles A, McLennan J, Rutter M, Bregman J, Folstein S, Fombonne E, Leboyer M, Minshew N: Diagnosing autism: analyses of data from the Autism Diagnostic Interview. J Autism Dev Disord 1997, 27:501-517.

57. Mulligan A, Richardson T, Anney RJ, Gill M: The Social Communication Questionnaire in a sample of the general population of school-going children. Ir J Med Sci 2009, 178:193-199.

58. St-Pierre A, Normandin L, Carrier G, Kennedy G, Butterworth R, Zayed J: Bioaccumulation and locomotor effect of manganese dust in rats. Inhal Toxicol 2001, 13:623-632.

59. Tong IS, Lu Y: Identification of confounders in the assessment of the relationship between lead exposure and child development. Ann Epidemiol 2001, 11:38-45.

60. SAS Institute I: SAS ${ }^{\oplus}$ 9.3. NC, SAS Institute, Inc; 2011.

61. Smargiassi A, Mutti A: Peripheral biomarkers and exposure to manganese. Neurotoxicology 1999, 20:401-406.

62. Baldwin M, Mergler D, Larribe F, Belanger S, Tardif R, Bilodeau L, Hudnell K: Bioindicator and exposure data for a population based study of manganese. Neurotoxicology 1999, 20:343-353.

63. Afridi HI, Kazi TG, Kazi N, Kandhro GA, Shah AQ, Baig JA, Wadhwa SK, Khan $\mathrm{S}$, Kolachi NF, Shah F, Jamali MK, Arain MB: Chromium and manganese levels in biological samples of normal and night blindness children of age groups (3-7) and (8-12) years. Biol Trace Elem Res 2011, 143:103-115.

64. Batterman S, Su FC, Jia C, Naidoo RN, Robins T, Naik I: Manganese and lead in children's blood and airborne particulate matter in Durban, South Africa. Sci Total Environ 2011, 409:1058-1068.

65. Rollin H, Mathee A, Levin J, Theodorou P, Wewers F: Blood manganese concentrations among first-grade schoolchildren in two South African cities. Environ Res 2005, 97:93-99.

66. Gulson B, Mizon K, Taylor A, Korsch M, Stauber J, Davis JM, Louie H, Wu M, Swan $\mathrm{H}$ : Changes in manganese and lead in the environment and young children associated with the introduction of methylcyclopentadienyl manganese tricarbonyl in gasoline-preliminary results. Environ Res 2006, 100:100-114.

67. Haynes EN, Ryan P, Chen A, Brown D, Roda S, Kuhnell P, Wittberg D, Terrell M, Reponen T: Assessment of personal exposure to manganese in children living near a ferromanganese refinery. Sci Total Environ 2012, 427-428:19-25.

68. Centers for Disease Control and Prevention: National Health and Nutrition Examination Survey (NHANES) 2011-2012 Laboratory Data. Centers for Disease Control and Prevention; 2013. http://www.cdc.gov/nchs/nhanes/ nhanes2011-2012/PbCd_G.htm 
69. Collipp PJ, Chen SY, Maitinsky S: Manganese in infant formulas and learning disability. Ann Nutr Metab 1983, 27:488-494.

70. Chan AW, Minski MJ, Lim L, Lai JC: Changes in brain regional manganese and magnesium levels during postnatal development: modulations by chronic manganese administration. Metab Brain Dis 1992, 7:21-33.

71. Spencer A: Whole blood manganese levels in pregnancy and the neonate. Nutrition 1999, 15:731-734.

72. Santos-Burgoa C, Rios C, Mercado LA, Arechiga-Serrano R, Cano-Valle F, Eden-Wynter RA, Texcalac-Sangrador JL, Villa-Barragan JP, Rodriguez-Agudelo Y, Montes S: Exposure to manganese: health effects on the general population, a pilot study in central Mexico. Environ Res 2001, 85:90-104

73. Claus Henn B, Schnaas L, Ettinger AS, Schwartz J, Lamadrid-Figueroa H, Hernandez-Avila M, Amarasiriwardena C, Hu H, Bellinger DC, Wright RO, Tellez-Rojo MM: Associations of early childhood manganese and lead coexposure with neurodevelopment. Environ Health Perspect 2012, 120:126-131.

74. Burger J, Gochfeld M: Heavy metals in commercial fish in New Jersey. Environ Res 2005, 99:403-412.

75. Zodape GV, Dhawan VL, Wagh RR, Sawant AS: Contamination of heavy metals in seafood marketed from Vile Parle and Dadar markets of suburban areas of Mumbai (west coast of) India. Int J Environ Sci 2011, 1:1177-1185.

76. Kumar B, Verma VK, Naskar AK, Chakraborty P, Shah R: Human Health Hazard due to Metal Uptake via Fish Consumption from Coastal and Fresh Water Waters in Eastern India Along the Bay of Bengal. J Mar Biol Oceanogr 2013, 2.

77. Pieniak Z, Verbeke W, Scholderer J: Health-related beliefs and consumer knowledge as determinants of fish consumption. J Hum Nutr Diet 2010, 23:480-488.

78. Burger J, Gochfeld M: Perceptions of the risks and benefits of fish consumption: individual choices to reduce risk and increase health benefits. Environ Res 2009, 109:343-349.

79. Zheng W, Fu SX, Dydak U, Cowan DM: Biomarkers of manganese intoxication. Neurotoxicology 2011, 32:1-8.

80. Agency for Toxic Substances and Disease Registry (ATSDR): Public Health Statement - Manganese. CAS \# 7439-96-5. Atlanta, GA: Agency for Toxic Substances and Disease Registry; 2012. http://www.atsdr.cdc.gov/ ToxProfiles/tp151-c1-b.pdf.

81. Palmer RF: Conclusions should be based on appropriate methodologies. Pediatrics 2010, 126. http://pediatrics.aappublications.org/content/126/4/ 656\#responses.

doi:10.1186/1476-069X-13-69

Cite this article as: Rahbar et al:: Blood manganese concentrations in Jamaican children with and without autism spectrum disorders. Environmental Health 2014 13:69.

\section{Submit your next manuscript to BioMed Central and take full advantage of:}

- Convenient online submission

- Thorough peer review

- No space constraints or color figure charges

- Immediate publication on acceptance

- Inclusion in PubMed, CAS, Scopus and Google Scholar

- Research which is freely available for redistribution

Submit your manuscript at www.biomedcentral.com/submit
Ciomed Central 